\title{
Stimmungsbilder von der Langen Nacht der Museen am 15. März 2014
}

Zum zehnten Mal in Folge beteiligte sich die Württembergische Landesbibliothek an der Langen Nacht der Museen und bot den 1.363 Besuchern ein abwechslungsreiches Programm mit Führungen, Präsentationen, Livemusik und kulinarischen Speisen. Für die musikalische Unterhaltung sorgte Jason Falloon mit Band, der bereits vor drei Jahren seine Premiere in der WLB hatte. Sein kraftvoller, kehliger Power-Gesang und das geniale Gitarrenspiel prägten erneut seine Rocksongs und ausdrucksstarken Balladen. Als äußerst beliebter „Dauerbrenner" erwiesen sich einmal mehr die
Magazinführungen, welche 291 Gäste in Anspruch nahmen. Die Welt der Digitalisierung lockte über 50 Besucher in die Räumlichkeiten der Digitalisierungswerkstatt, während im Vortragsraum viele die Möglichkeit nutzten, spannende Dokumente aus dem Ersten Weltkrieg zu entdecken. Kalt und gruselig ging es bei der Lesung zur Mitternacht von Petra Sauer und Eva Hornberger zu, die 40 Besucher im Hauptlesesaal gespannt verfolgten. Pate standen hier bekannte Autoren wie $\mathrm{H}$. P. Lovecraft, A. Bierce und E. A. Poe. Einbände aus 1.000 Jahren im Buchmuseum rundeten das vielfältige Angebot ab. Trotz einem unfreiwilligen Feuerwehreinsatz am Spätnachmittag, ausgelöst vom Grill in der Cafeteria, kamen die Gäste auch kulinarisch auf ihre Kosten; kontinuierliche Erfrischung für jeden Geschmack spendeten auch in diesem Jahr die Bierbar sowie die „Bibliotheke". Zu danken ist wieder einmal der Württembergischen Bibliotheksgesellschaft, die durch ihre finanzielle Unterstützung die "Lange Nacht" in dieser Form ermöglicht hat.

[Fotos: Susanne Vetter]

\section{Jörg Ennen}

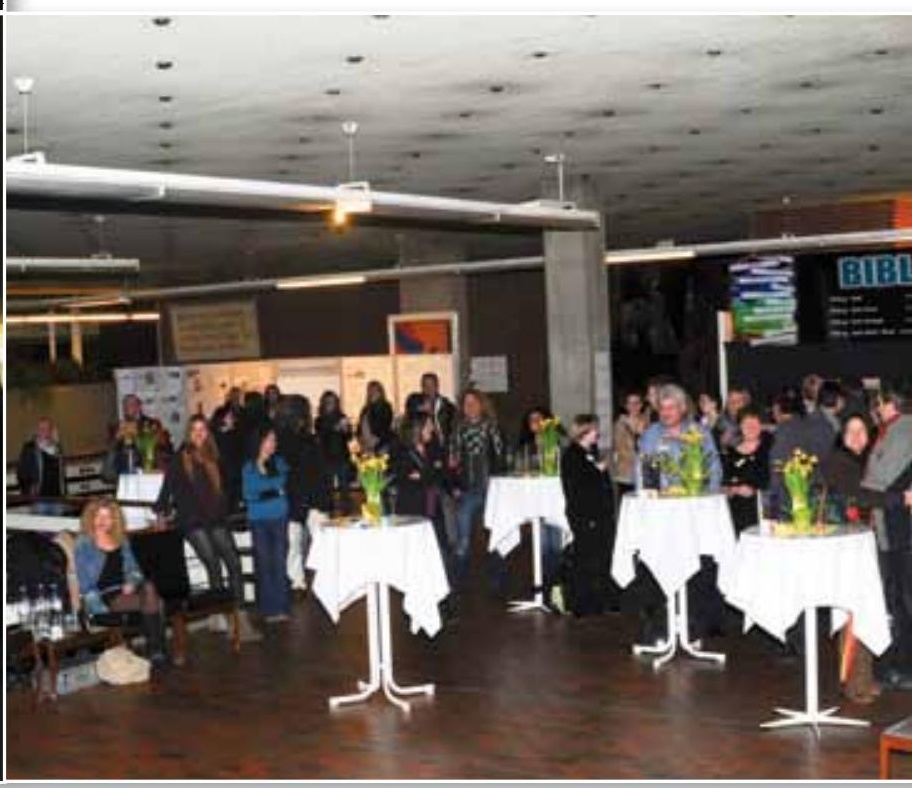


